\title{
Low apparent activation energy of ammonia synthesis over Ru catalyst supported by hydrogen storage material
}

Kazuma Torii, ${ }^{\dagger}$ Takaya Ogawa, ${ }^{\dagger,}{ }^{*}$ Ryusei Morimoto, Tetsu Seno, Hideyuki Okumura, Keiichi N. Ishihara

${ }^{\dagger} \mathrm{K}$. T. and T. O. contributed equally to this work.

*Corresponding author. Email: ogawa.takaya.8s@kyoto-u.ac.jp

\begin{abstract}
Ruthenium is an excellent catalyst for ammonia synthesis and recently shows quite high activity when supported on materials with high electron-donating and hydrogen-absorbing properties. The high activity is generally considered to originate from the two effects: the electron-donating property of the support, which reduces its apparent activation energy $\left({ }^{\text {app }} \mathrm{E}_{\mathrm{a}}\right.$ ) to half of pure $\mathrm{Ru}{ }^{\prime}{ }^{\mathrm{app}} \mathrm{E}_{\mathrm{a}}$, and the hydrogen-absorbing property, which increases the active site by suppressing hydrogen poisoning, a drawback of ruthenium catalysts. Here, we investigated the catalytic performance of ruthenium loaded on $\mathrm{TiMn}_{2}$, a hydrogen storage material without electron-donating property to ruthenium. Ruthenium on $\mathrm{TiMn}_{2}$ showed the ${ }^{\mathrm{app}} \mathrm{E}_{\mathrm{a}}$ reduced by half despite the lack of electron-donating property. It is plausible that the decreased ${ }^{\text {app }} \mathrm{E}_{\mathrm{a}}$ is due to the elimination of hydrogen over $\mathrm{Ru}$ by $\mathrm{TiMn}_{2}$. The hydrogen storage capacity is also an essential factor in discussing the ${ }^{a p p} \mathrm{E}_{\mathrm{a}}$.
\end{abstract}

\section{Introduction}

Ammonia is indispensable for human beings as an artificial fertilizer and is one of the most produced chemicals. The amount of ammonia production is more than 182 million tonnes in 2019 and is expected to increase by $4 \%$ during the next four years ${ }^{1}$. Ammonia has been industrially synthesized at 400-500 ${ }^{\circ} \mathrm{C}$ and $10-30 \mathrm{MPa}$ using an Fe-based catalyst for over 100 years ${ }^{2,3}$. However, these severe conditions require a large, robust, and expensive plant. Therefore, the business model is the synthesis at a large scale and distribution ammonia to each area. It results in scarce fertilizer in many countries that do not have sufficient transport infrastructures, such as Zambia, Tanzania, Ghana, and Nigeria ${ }^{4,5}$. The milder reaction condition would realize ammonia synthesis at a small scale and supply ammonia to local agricultural lands, making the fertilizer cost affordable, increasing food production, and reducing starvation.

Ru has been known to synthesize ammonia with high activity when the electropositive metal is added, although the fatal drawback of $\mathrm{Ru}$ is hydrogen poisoning ${ }^{3,6-9}$. It was recently reported that $\mathrm{Ru}$ supported on oxyhydride- and oxynitride-based materials are highly reactive even under mild conditions ${ }^{10-14}$. For example, Ru supported on electride $\left[\mathrm{Ca}_{24} \mathrm{Al}_{28} \mathrm{O}_{64}\right]^{4+}\left(\mathrm{e}^{-}\right)_{4}\left(\mathrm{Ru} / \mathrm{C} 12 \mathrm{~A} 7: \mathrm{e}^{-}\right)$shows 
high reactivity, ${ }^{15}$ where $\mathrm{C} 12 \mathrm{~A} 7: \mathrm{e}^{-}$has two characteristic properties: one is the hydrogen storage capacity, which suppresses hydrogen poisoning and increases the number of active Ru sites. The other is the high electron-donating property, which reduces the apparent activation energy ( ${ }^{a p p} \mathrm{E}_{\mathrm{a}}$ ) to half of $\mathrm{Ru}$ bulk's ${ }^{\mathrm{app}} \mathrm{E}_{\mathrm{a}}$ and enhances the reaction rate. There are many reports similar to this, and electrondonating properties are generally considered an important factor in lowering ${ }^{a p p} \mathrm{E}_{\mathrm{a}}$.

Meanwhile, the coverage of hydrogen and nitrogen has a dependency on temperature ${ }^{16}$. For example, with the adsorption-desorption reaction of species A given by

$$
A+* \rightarrow A^{*}
$$

Where ${ }^{*}$ means an unoccupied site. We can associate the reaction fraction, $\theta_{\mathrm{A}} / \mathrm{p}_{\mathrm{A}} \theta_{*}$, where $\theta_{\mathrm{A}}$ is a fractional coverage of the adsorbate $\mathrm{A}$ on the surface, $\mathrm{p}_{\mathrm{A}}$ is a pressure of gas $\mathrm{A}$, and a probability that a site is unoccupied, $\theta *$. At equilibrium, we have

$$
\left.\frac{\theta_{A}}{p_{A} \theta_{*}}\right|_{E q}=K_{a d s}=e^{-\frac{\Delta G_{a d s}}{k_{B} T}}
$$

where $\mathrm{K}_{\mathrm{ads}}$ is an equilibrium constant of the adsorption, $\Delta \mathrm{G}_{\mathrm{ads}}$ is the change of Gibbs free energy by the adsorption of $\mathrm{A}, \mathrm{k}_{\mathrm{B}}$ is Boltzmann constant, and $\mathrm{T}$ is temperature. Then, the coverage depends on temperature and directly determines reaction rates. In the case that the rate-determining step is the reaction, $\mathrm{A}^{*}+\mathrm{B}^{*} \rightarrow \mathrm{AB}^{*+*}$, a reaction rate, $\mathrm{r}_{\mathrm{AB}}$, is described as follows

$$
\mathrm{r}_{A B}=\mathrm{k}_{A B} \theta_{A} \theta_{B}
$$

where $\mathrm{k}_{\mathrm{AB}}$ is a reaction constant for the reaction. Therefore, ${ }^{a p p} \mathrm{E}_{\mathrm{a}}$, estimated by the temperature dependence of $\mathrm{k}_{\mathrm{AB}}$, is influenced by the coverage through the equation below:

$$
{ }^{a p p} E_{a}=-\frac{\partial\left(\ln r_{A B}\right)}{\partial\left(1 / k_{B} T\right)}=-\frac{\partial\left(\ln k_{A B}+\ln \theta_{A}+\ln \theta_{B}\right)}{\partial\left(1 / k_{B} T\right)}=E_{a}-\frac{\partial\left(\ln \theta_{A}+\ln \theta_{B}\right)}{\partial\left(1 / k_{B} T\right)}
$$

As well as the assumed reaction, the hydrogen storage ability itself can change $\theta_{\mathrm{H}}$, increasing the coverage of other species and changing the ${ }^{a p p} \mathrm{E}_{\mathrm{a}}$. However, the influence of hydrogen storage ability on ${ }^{\text {app }} \mathrm{E}_{\mathrm{a}}$ has not been discussed for the recent catalysts.

In this paper, we prepared $\mathrm{Ru}$ on hydrogen storage material, $\mathrm{TiMn}_{2}$. The work functions of $\mathrm{Ti}, \mathrm{Mn}$, and $\mathrm{Ru}$ are $4.3,4.1$, and $4.7 \mathrm{eV}$, respectively, which are or similar values and hardly donates an electron to $\mathrm{Ru}$ from $\mathrm{TiMn}_{2}$. Thus, the function of only hydrogen storage ability on ${ }^{\text {app }} \mathrm{E}_{\mathrm{a}}$ can be estimated. The $1-10 \mathrm{wt} \%$ of $\mathrm{Ru}$ on $\mathrm{TiMn}_{2}$ catalysts were prepared to demonstrate the influence of the $\mathrm{Ru} / \mathrm{TiMn}_{2}$ ratio. For comparisons, $\mathrm{Ru}$ bulk and $\mathrm{Ru}$ dispersed on carbon and $\mathrm{MgO}$ were investigated. To discuss the effect of electron donation to $\mathrm{Ru}$ on ${ }^{\mathrm{app}} \mathrm{E}_{\mathrm{a}}, \mathrm{K}$ was added as an electropositive metal.

\section{Experimental methods}

The preparation of catalysts The powder of $\operatorname{TiMn}_{2}(\mathrm{Mn}: \sim 51 \%$, Ti: 29\%, V: 14\%, Fe, Cr, Zr: $\sim 6 \%$, Sigma-Aldrich Co. LLC) was prepared by only hand milling with an alumina mortar and pestle. The work function of $\mathrm{V}, \mathrm{Fe}, \mathrm{Cr}$, and $\mathrm{Zr}$ are 4.3, 4.5, 4.5, and $4.1 \mathrm{eV}$, respectively, and are considered not to 
donate electrons to $\mathrm{Ru}$. Ruthenium (III) acetylacetonate $\left(\mathrm{Ru}(\mathrm{acac})_{3}\right.$, Strem Chemicals, Inc) was dissolved in pentane. The $\mathrm{TiMn}_{2}$ powder was dispersed in the solution and evaporated in a vacuum at elevated temperature with staring. The amount of loaded Ru was 1, 3, $510 \mathrm{wt} \%$ (Xwt\%Ru/TiMn 2 when Xwt\% of Ru was loaded). 1wt\% Ru on $\mathrm{MgO}$ (99.9\%, Kojundo Chemical Lab. Co., Ltd., $1 \mathrm{wt} \% \mathrm{Ru} / \mathrm{MgO}$ ) and $10 \mathrm{wt} \% \mathrm{Ru}$ on carbon (99.9\%, Kojundo Chemical Lab. Co., Ltd., 10wt\%Ru/C) were prepared in the same way using $\mathrm{Ru}(\mathrm{acac})_{3}$, where $\mathrm{MgO}$ and $\mathrm{C}$ were employed not to have electron donation and hydrogen storage properties. When $\mathrm{K}$ was added to $10 \mathrm{wt} \% \mathrm{Ru} / \mathrm{TiMn}_{2}$ or $\mathrm{Ru}$, $10 \mathrm{wt} \% \mathrm{Ru} / \mathrm{TiMn}_{2}$ or $\left(\mathrm{Ru}(\mathrm{acac})_{3}\right)$ were dispersed or dissolved in N,N-dimethylformamide, respectively. $\mathrm{KNO}_{3}$ (99.9\%, Fujifilm Wako Pure Chemical Corporation) was added to each solution and evaporated in a vacuum at elevated temperature with staring, adjusting the ratio of $\mathrm{Ru}$ and $\mathrm{K}$ to $1: 1$ (10wt\% $\mathrm{Ru}+\mathrm{K} / \mathrm{TiMn}_{2}$ or $\mathrm{Ru}+\mathrm{K}$, respectively). $\mathrm{K}$ was added to the $\mathrm{TiMn}_{2}$ powder, in the same way, adjusting the $\mathrm{K}$ and $\mathrm{TiMn}_{2}$ ratio to the same with $10 \mathrm{wt} \% \mathrm{Ru}+\mathrm{K} / \mathrm{TiMn}$. For a comparison, Ru powder (Ru bulk, $\leq 0.3 \mu \mathrm{m}$ (TRU-300), Tokuriki-Honten CO. LTD) was tested as purchased. The temperature range of app $\mathrm{E}_{\mathrm{a}}$ measurement was $340-420^{\circ} \mathrm{C}$.

The characterization of properties The Brunauer-Emmett-Teller (BET) specific surface areas of the samples were determined from nitrogen adsorption-desorption isotherms measured at $-196{ }^{\circ} \mathrm{C}$ using an automatic gas-adsorption instrument: (Gemini VII 2390, Micromeritics)

The characterization of catalytic activity The reactivities of the catalysts were demonstrated in a stainless-steel flow set-up. Supplied gas is an extrapure (99.9999\%) mixture of $\mathrm{H}_{2}, \mathrm{~N}_{2}$, and Ar. Before the reactions, all the catalysts were treated in a stream of $\mathrm{N}_{2}: \mathrm{H}_{2}=1: 3$ under $0.1 \mathrm{MPa}$, raising reaction temperature by $200{ }^{\circ} \mathrm{C} \mathrm{h}^{-1}$. The concentration of ammonia in the stream that left the catalyst bed was monitored under steady-state temperature conditions. The ammonia produced was trapped in $5 \mathrm{mM}$ sulfuric acid solution. The amount of $\mathrm{NH}_{4}{ }^{+}$in the solution was determined using an ion chromatograph (Eco IC, Metrohm) equipped with a conductivity detector.

Kinetic Analysis The reaction orders of $\mathrm{N}_{2}(\alpha), \mathrm{H}_{2}(\beta)$, and $\mathrm{NH}_{3}(\gamma)$ was determined by changing the flow ratio of $\mathrm{H}_{2}, \mathrm{~N}_{2}$, and $\mathrm{Ar}$ in the similar way with previous publication ${ }^{17}$ with the equation below.

$$
\mathrm{r}=\mathrm{k} P_{\mathrm{N}_{2}}{ }^{\alpha}{P_{\mathrm{H}_{2}}}^{\beta} P_{\mathrm{NH}_{3}}{ }^{\gamma}
$$

The analysis was conducted at $0.1 \mathrm{MPa}$ and $400{ }^{\circ} \mathrm{C}$.

\section{Results}

The catalytic activities for ammonia synthesis were summarized in Table 1 . The $1-10 \mathrm{wt} \% \mathrm{Ru} / \mathrm{TiMn}_{2}$ showed the reduced ${ }^{\text {app }} \mathrm{E}_{\mathrm{a}}$, mostly the half of Ru bulk's ${ }^{\text {app }} \mathrm{E}_{\mathrm{a}}$. $\mathrm{TiMn}_{2}$ without Ru exhibited negligible activity. In addition, $1 \mathrm{wt} \% \mathrm{Ru} / \mathrm{MgO}$ and $10 \mathrm{wt} \% \mathrm{Ru} / \mathrm{C}$ did not possess such low ${ }^{a p p} \mathrm{E}_{\mathrm{a}}$. Hence, the combination of $\mathrm{TiMn}_{2}$ and $\mathrm{Ru}$ causes the low ${ }^{\mathrm{app}} \mathrm{E}_{\mathrm{a}}$. Interestingly, the less amount of Ru loading on $\mathrm{TiMn}_{2}$ is, the less ${ }^{\mathrm{app}} \mathrm{E}_{\mathrm{a}}$ were detected. However, the reaction rate is high when the $\mathrm{Ru}$ amount is high. It should be reasonable that a low ${ }^{a p p} \mathrm{E}_{\mathrm{a}}$ does not result in a high reaction rate. 
Table 1 Performance of catalysts for ammonia synthesis

\begin{tabular}{|c|c|c|c|}
\hline \multicolumn{1}{c|}{ Catalyst } & $\begin{array}{c}\mathrm{NH}_{3} \text { synthesis rate } \\
\left(\mu \mathrm{mol} \mathrm{g}{ }^{-1} \mathrm{~h}^{-1}\right)\end{array}$ & $\begin{array}{c}\text { BET surface area } \\
\left(\mathrm{m}^{2} \mathrm{~g}^{-1}\right)\end{array}$ & $\begin{array}{c}{ }^{\text {app }} \mathrm{E}_{\mathrm{a}} \\
\left(\mathrm{kJ} \mathrm{mol}^{-1}\right)\end{array}$ \\
\hline $\mathrm{TiMn}_{2}$ & Negligible & 0.41 & - \\
\hline $1 \mathrm{wt} \% \mathrm{Ru} / \mathrm{TiMn}_{2}$ & 25 & 1.64 & 44 \\
\hline $3 \mathrm{wt} \% \mathrm{Ru} / \mathrm{TiMn}_{2}$ & 86 & 0.85 & 56 \\
\hline $5 \mathrm{wt} \% \mathrm{Ru} / \mathrm{TiMn}_{2}$ & 130 & 0.73 & 68 \\
\hline $10 \mathrm{wt} \% \mathrm{Ru} / \mathrm{TiMn} 2$ & 141 & 0.52 & 67 \\
\hline $\mathrm{Ru} \mathrm{bulk}$ & 564 & 18.02 & $128^{\mathrm{b}}$ \\
\hline $1 \mathrm{wt} \% \mathrm{Ru} / \mathrm{MgO}$ & 156 & 5.22 & 87 \\
\hline $10 \mathrm{wt} \% \mathrm{Ru} / \mathrm{C}$ & 64 & 11.84 & 104 \\
\hline $\mathrm{TiMn}+\mathrm{K}$ & 21 & 0.18 & 78 \\
\hline $10 \mathrm{wt} \% \mathrm{Ru}+\mathrm{K} / \mathrm{TiMn}$ & 635 & 6.71 & 52 \\
\hline $\mathrm{Ru}+\mathrm{K}$ & 3828 & 4.35 & 80 \\
\hline
\end{tabular}

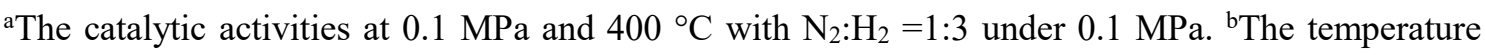
range of measurement is $372-435^{\circ} \mathrm{C}$.

When $\mathrm{K}$ was added to $\mathrm{TiMn}_{2}, \mathrm{Ru}$, and $\mathrm{Ru} / \mathrm{TiMn}_{2}$ catalysts, the activities of all catalysts were enhanced. $\mathrm{TiMn}_{2}+\mathrm{K}$ showed some reactivity, which is still negligible though and thus no need to be considered. For $10 \mathrm{wt} \% \mathrm{Ru}+\mathrm{K} / \mathrm{TiMn}_{2}$, the improved activity is attributed to the enlarged surface area, although the ${ }^{\text {app }} \mathrm{E}_{\mathrm{a}}$ decreased. $\mathrm{Ru}+\mathrm{K}$ showed the highest activity among the catalysts tested in this paper even though ${ }^{\text {app }} \mathrm{E}_{\mathrm{a}}$ is not the lowest. It is the same conclusion as the previous paragraph.

The reaction orders of $1 \mathrm{wt} \% \mathrm{Ru} / \mathrm{TiMn}_{2}$ and $\mathrm{Ru}+\mathrm{K}$ were measured (Table 2). As we expected, the reaction order for hydrogen over $1 \mathrm{wt} \% \mathrm{Ru} / \mathrm{TiMn}_{2}$ was positive, which means $\mathrm{TiMn}_{2}$ successfully suppressed hydrogen poisoning. In addition, $\mathrm{Ru}+\mathrm{K}$ also showed a positive reaction order for hydrogen. It means $\mathrm{K}$ also has a role in disturbing hydrogen poisoning.

Table 2 The reaction orders (see Eq. (5))

\begin{tabular}{c|ccc}
\hline \multirow{2}{*}{ Catalyst } & \multicolumn{4}{c}{ Reaction orders } \\
& $\alpha$ & $\beta$ & $\gamma$ \\
\hline $1 \mathrm{wt} \% \mathrm{Ru} / \mathrm{TiMn}_{2}$ & 0.95 & 1.19 & -0.80 \\
\hline $\mathrm{Ru}+\mathrm{K}$ & 1.26 & 1.04 & -0.55 \\
\hline
\end{tabular}

\section{Discussion}

Eq. (2) indicates that $\theta_{\mathrm{H}}$ decreases when the temperature is elevated, eliminating hydrogen poisoning and increasing $\theta_{N}$. The large $\theta_{N}$ enhances $r$ as well as Eq. (3), which leads to a high dependency of $r$ on temperature. The reaction order of $1 \mathrm{wt} \% \mathrm{Ru} / \mathrm{TiMn}_{2}$ was positive, and thus the hydrogen poisoning 
over the $\mathrm{Ru}$ supported by $\mathrm{TiMn}_{2}$ was overcome. It can be interpreted that the $\theta_{\mathrm{H}}$ was reduced not by temperature but by the $\mathrm{TiMn}_{2}$. Then, the dependence on temperature of $r$ was mitigated, which can result in low ${ }^{a p p} \mathrm{E}_{\mathrm{a}}$. In fact, the ${ }^{\mathrm{app}} \mathrm{E}_{\mathrm{a}} \mathrm{s}$ of $1-10 \mathrm{wtRu} / \mathrm{TiMn}_{2}$ catalysts decreased to almost half of the $\mathrm{Ru}$ bulk's app $\mathrm{E}_{\mathrm{a}}$. The lower ${ }^{\mathrm{app}} \mathrm{E}_{\mathrm{a}}$ can be explained by the hydrogen storage ability of support materials.

The density functional theory (DFT) calculation indicates the $\mathrm{E}_{\mathrm{a}}$ for ammonia synthesis over $\mathrm{Ru}$ without electron donation is around $100 \mathrm{~kJ} / \mathrm{mol}$, which is higher than the ${ }^{\mathrm{app}} \mathrm{E}_{\mathrm{a}} \mathrm{s}$ of the tested catalysts. It is possible that over Ru supported on hydrogen storage materials, $\theta *$ is dominant rather than $\theta_{\mathrm{H}}$ and $\theta_{\mathrm{N}}$. Therefore, the raised temperature induces both lower $\theta_{\mathrm{H}}$ and $\theta_{\mathrm{N}}$, which slowdowns $\mathrm{r}$ and mitigates the temperature dependency of $r$. It can decrease the ${ }^{a p p} E_{a}$ than the actual $E_{a}$.

The tendency of the ${ }^{\mathrm{app}} \mathrm{E}_{\mathrm{a}}$ among $1-10 \mathrm{wt} \% \mathrm{Ru} / \mathrm{TiMn}_{2}$ is also explained by the role of the hydrogen storage ability. In the case of the large amount of $\mathrm{Ru}$ on $\mathrm{TiMn}_{2}$, the amount of hydrogen stored in $\mathrm{TiMn}_{2}$ per Ru is less, and thus the hydrogen poisoning is not fully suppressed. Therefore, the large amount of $\mathrm{Ru}$ on $\mathrm{TiMn}_{2}$ results in the relatively high ${ }^{\mathrm{app}} \mathrm{E}_{\mathrm{a}}$. However, the reaction rate is faster on the catalysts with a larger Ru-loading amount but a smaller surface area. Besides, $\mathrm{Ru}+\mathrm{K}$ shows the highest activity among the tested catalysts even though its ${ }^{a p p} \mathrm{E}_{\mathrm{a}}$ is not smaller than $1-10 \mathrm{wt} \% \mathrm{Ru} / \mathrm{TiMn}_{2}$. We should conclude that the discussion on ${ }^{a p p} \mathrm{E}_{\mathrm{a}}$ is not suitable to associate with the reaction rate directly.

The hydrogen poisoning over $\mathrm{Ru}+\mathrm{K}$ was suppressed, as shown by the reaction order of hydrogen over $\mathrm{Ru}+\mathrm{K}$. In addition, the $10 \mathrm{wt} \% \mathrm{Ru}+\mathrm{K} / \mathrm{TiMn}_{2}$ exhibits the less ${ }^{\mathrm{app}} \mathrm{E}_{\mathrm{a}}$ than that of $10 \mathrm{wt} \% \mathrm{Ru} / \mathrm{TiMn}_{2}$. Then, the reduced ${ }^{\mathrm{app}} \mathrm{E}_{\mathrm{a}}$ of $\mathrm{Ru}+\mathrm{K}$ can be explained by electron donation from $\mathrm{K}$ and storing hydrogen. It would be concluded that both electro-donating and hydrogen storage properties have an enormous influence on an ${ }^{a p p} \mathrm{E}_{\mathrm{a}}$. According to the XANES spectrum in the previous report ${ }^{18}$, the $\mathrm{K}$-edge of $\mathrm{Ru}$ on $\mathrm{C} 12 \mathrm{~A} 7: \mathrm{e}^{-}$did not shift to lower energy, which means electrons were not donated to $\mathrm{Ru}$ from $\mathrm{C} 12 \mathrm{~A} 7: \mathrm{e}^{-}$although the $\mathrm{N} \equiv \mathrm{N}$ bonding on $\mathrm{Ru} / \mathrm{C} 12 \mathrm{~A} 7: \mathrm{e}^{-}$is weakened at $-170^{\circ} \mathrm{C}$ under 5 $\mathrm{kPa}$ of $\mathrm{N}_{2}{ }^{15}$. The ${ }^{\text {app }} \mathrm{E}_{\mathrm{a}}$ of $\mathrm{Ru} / \mathrm{C} 12 \mathrm{~A} 7: \mathrm{e}^{-}$is around $40 \mathrm{~kJ} / \mathrm{mol}$ at the lowest, similar to the ${ }^{\text {app }} \mathrm{E}_{\mathrm{a}}$ of $1 \mathrm{wt} \% \mathrm{Ru} / \mathrm{TiMn}_{2}$. Recent progress of catalysts associated with much-reduced ${ }^{\mathrm{app}} \mathrm{E}_{\mathrm{a}}$ of ammonia synthesis might be explained by the influence of the hydrogen storage ability.

\section{Conclusion}

The catalytic performance of ammonia synthesis over Ru supported by hydrogen storage alloy, $\mathrm{TiMn}_{2}$, was examined to estimate the influence of only hydrogen storage property on ${ }^{a p p} \mathrm{E}_{\mathrm{a}}$. The positive reaction orders of hydrogen on $\mathrm{Ru} / \mathrm{TiMn}_{2}$ indicate that the hydrogen poisoning over the $\mathrm{Ru}$ on $\mathrm{TiMn}_{2}$ is suppressed. $\mathrm{Ru} / \mathrm{TiMn}_{2}$ catalysts exhibit low ${ }^{\text {app }} \mathrm{E}_{\mathrm{a}}$, almost half of Ru bulk's app $\mathrm{E}_{\mathrm{a}}$. The decreased $\theta_{\mathrm{H}} \mathrm{S}$ over $\mathrm{Ru}$ derived from hydrogen storage properties are considered to reduce their ${ }^{\mathrm{app}} \mathrm{E}_{\mathrm{a}}$. Besides, even if the ${ }^{\mathrm{app}} \mathrm{E}_{\mathrm{a}}$ is not low, the reaction rate can be high according to the results of $1-10 \mathrm{wt} \% \mathrm{Ru} / \mathrm{TiMn}_{2}$ and 
$\mathrm{Ru}+\mathrm{K}$. Hydrogen storage properties should be included to discuss reduced ${ }^{\mathrm{app}} \mathrm{E}_{\mathrm{a}}$, which would give the correct direction to design a new catalyst of ammonia synthesis.

\section{Acknowledgment}

This research was supported by the Environment Research and Technology Development Fund (JPMEERF20192R02) of the Environmental Restoration and Conservation Agency of Japan.

\section{Reference}

(1) Survey, U. S. G. Mineral Commodity Summaries 2020, 2020.

(2) Liu, H. Z. Chin. J. Catal. 2014, 35, 1619.

(3) Liu, H. Ammonia synthesis catalysts : innovation and practice; Chemical Industry Press World Scientific, 2013.

(4) Morris, M. L. Fertilizer Use in African Agriculture: Lessons Learned and Good Practice Guidelines; World Bank, 2007.

(5) Chauhan, M. Nexant 2018, 1.

(6) Aika, K.; Ozaki, A.; Hori, H. J. Catal. 1972, 27, 424.

(7) Saadatjou, N.; Jafari, A.; Sahebdelfar, S. Chem. Eng. Commun. 2015, 202, 420.

(8) Aika, K.-i. Catal. Today 2017, 286, 14.

(9) Ogawa, T.; Kobayashi, Y.; Mizoguchi, H.; Kitano, M.; Abe, H.; Tada, T.; Toda, Y.; Niwa, Y.; Hosono, H. J. Phys. Chem. C 2018, 122, 10468.

(10) Hara, M.; Kitano, M.; Hosono, H. ACS Catal. 2017, 7, 2313.

(11) Ye, T.-N.; Park, S.-W.; Lu, Y.; Li, J.; Sasase, M.; Kitano, M.; Tada, T.; Hosono, H. Nature 2020, 583, 391.

(12) Hattori, M.; Iijima, S.; Nakao, T.; Hosono, H.; Hara, M. Nat Commun 2020, 11, 2001.

(13) Wang, P.; Chang, F.; Gao, W.; Guo, J.; Wu, G.; He, T.; Chen, P. Nat Chem 2017, 9, 64.

(14) Kobayashi, Y.; Tang, Y.; Kageyama, T.; Yamashita, H.; Masuda, N.; Hosokawa, S.; Kageyama, H. J Am Chem Soc 2017, 139, 18240.

(15) Kitano, M.; Inoue, Y.; Yamazaki, Y.; Hayashi, F.; Kanbara, S.; Matsuishi, S.; Yokoyama, T.; Kim, S. W.; Hara, M.; Hosono, H. Nat. Chem. 2012, 4, 934.

(16) Nørskov, J. K.; Studt, F.; Abild-Pedersen, F.; Bligaard, T. Fundamental Concepts in Heterogeneous Catalysis; Wiley, 2014, 68

(17) Kojima, R.; Aika, K. Appl. Catal. A-Gen. 2001, 218, 121.

(18) Abe, H.; Niwa, Y.; Kitano, M.; Inoue, Y.; Murakami, Y.; Yokoyama, T.; Hara, M.; Hosono, H. J. Phys. Chem. C 2016, 120, 8711. 